\title{
Characterization of Mixture Distribution and Combustion in a DISI Optical Engine Under Late Injection Mode
}

\author{
Dong-Seok Choi, Yongseok Lee, Jaejoon Choi and Choongsik Bae
}

Korea Advanced Institute of Science and Technology

373-1, Kusong-Dong, Yusong-Gu, Daejon 305-701, Korea

\begin{abstract}
This study investigated combustion characteristics paying particular attention to a mass flow rate pattern under stratification charge mode. The mass flow rate was changed using two injector drivers with different operating characteristics for an injector. These injection systems were employed in an optical single-cylinder engine. Three different injection timings under late injection modes were set to simulate the stratification charge combustion. To obtain the mass flow rate, the experiments of fuel metering and injection rate measurement were performed with a fixed injection quantity. In-cylinder pressure was measured to analyze combustion characteristics. Initial flame size and its developments were also visualized. In addition, the mixture distribution prior to ignition was obtained using PLIF technique. As the mass flow rate has a higher value, more stable and faster combustion was achieved. The mixture distribution showed more uniform and higher concentration in the bowl near the spark plug as the mass flow rate increases.
\end{abstract}

\section{Introduction}

The performance of Direct-Injection Spark Ignition (DISI) engines, especially at part loads, depends on the dynamic characteristics of fuel injection system. In other words, a mass flow rate of the injection system has a significant effect on stratified combustion under light load operating conditions $[1,2]$. Hence, the characteristics of the mass flow rate obtained from the fuel injection rate are extremely important in designing the DISI engines.

For stable stratified combustion, the spray characteristics determined by the mass flow rate must provide the proper development of a mixture distribution which will maintain combustion after ignition. In addition, it is necessary to concentrate the appropriate air/fuel mixture around the spark plug for stable flame propagation [3, 4]. It has been considered difficult to achieve stable combustion over a wide range of operating conditions since the permissible range of mixture concentrations is narrow.

The control of the mass flow rate is, therefore, very important since it governs the combustion rate and pollutant formation. Short injection durations less than $1 \mathrm{~ms}$ are recently required to solve emission problems in two-stage injection strategy [5,6]. It could be possible to apply the split injection of more than two times as another injection strategy for lean combustion. Thus, the effect of the mass flow rate on the mixture distribution and combustion characteristics needs to be 
clarified to achieve the stable combustion and reduction of pollutant emissions.

The objective of this study is to investigate combustion characteristics paying particular attention to the mass flow rate patterns under stratification charge mode. For this aim, the mass flow rate was varied using two injector drivers with the different operating characteristics for an injector. These injection systems were employed in an optical single-cylinder engine. Three different injection timings under late injection conditions were tested to simulate the stratification charge combustion. To obtain the mass flow rate, the experiments of fuel metering and injection rate measurement were performed at a fixed air-fuel ratio. In-cylinder pressure was measured to analyze combustion characteristics. Initial flame size and its developments were visualized. In addition, the mixture distribution prior to ignition was also obtained using Planar Laser Induced Fluorescence (PLIF) technique. From these experimental results, the effect of the mass flow rate on combustion and mixture distribution was examined under late injection mode.

\section{Experimental setup}

\subsection{Optical engine}

The experiments were performed in an optical single cylinder engine modified from a production engine. As shown in Fig. 1, the research engine consists of cylinder head, visualization modules in the extended piston and liner, two connecting plates and cylinder block. A specially designed intake port induces a strong reverse tumble which guides the injected fuel with the help of the special piston bowl to the spark plug. Figure 2 shows the details of a piston top. Flame and fuel inside of the piston bowl were visualized through the bottom view window and optical prism. In the PLIF experiments, this prism plays a role in turning laser sheet horizontally into the inside of the piston bowl. In Fig. 2(a), the observation area was confined by the bottom view window. A high-pressure swirl injector with a cone angle of $60^{\circ}$ was used for gasoline direct injection. Table 1 summarizes the engine specification.

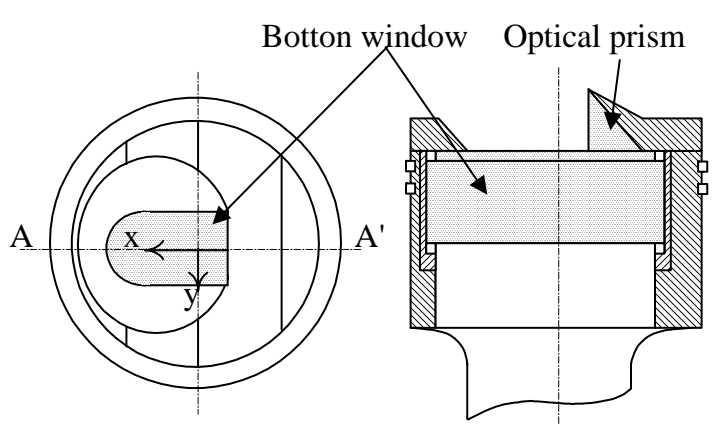

(a) Top view

(b) Cross section view ( A-A')

Figure 2 Configuration of piston top

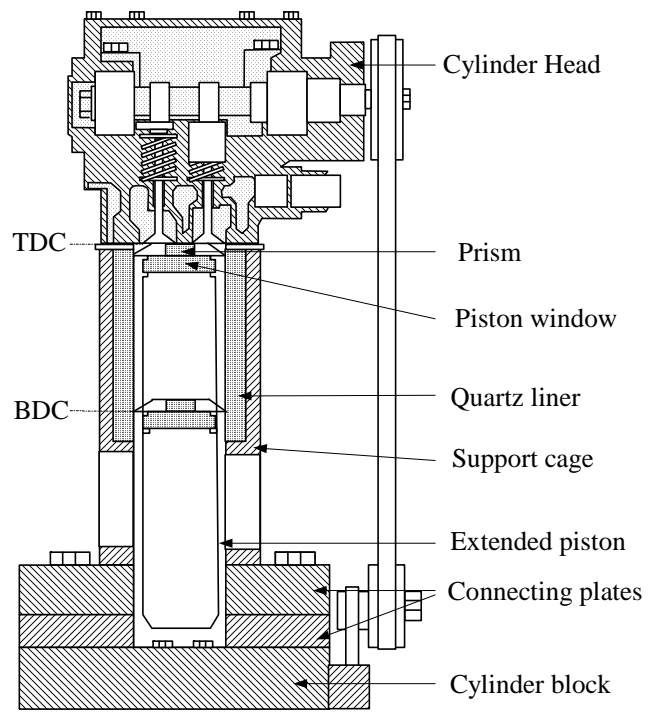

Figure 1 Schematic of an optical engine

Table 1 Specifications of the optical engine

\begin{tabular}{l|l}
\hline Engine Type & 4 stroke, 4 valve \\
\hline Bore $\times$ Stroke $(\mathrm{mm})$ & $85 \times 88$ \\
\hline Displacement vol. $(\mathrm{cc})$ & 559 \\
\hline Combustion chamber & Pent-roof \\
\hline Compression ratio & 9.3 \\
\hline \multirow{4}{*}{ Valve timing } & IVO: $6^{\circ}$ BTDC, \\
& IVC: $46^{\circ}$ ABDC \\
\cline { 2 - 2 } & EVO: $130^{\circ}$ ATDC, \\
\hline Injector type & EVC: $10^{\circ}$ ATDC \\
\hline Ignition method & Hollow cone, $60^{\circ}$ swirl \\
\hline
\end{tabular}




\subsection{Measurements}

The engine was operated at 800rpm. The coolant temperature was set at $70^{\circ} \mathrm{C}$. Iso-octane was used as fuel. Air-fuel ratio was fixed at 35 for all experiments. Injection pressure was set at $5 \mathrm{MPa}$ by compressed nitrogen. Three different injection timings $\left(50^{\circ} \mathrm{BTDC}, 60^{\circ} \mathrm{BTDC}\right.$ and $\left.70^{\circ} \mathrm{BTDC}\right)$ were set to investigate the effect of injection timing on fuel stratification. MBT spark timings for each injection timing were found. Combustion analysis was conducted by calculating from in-cylinder pressure through the engine test without the optical modules.

The mass flow rate characteristics of the injector were obtained by independently measuring the relative momentum of the fuel spray and the total mass of fuel injected. The relative spray momentum was measured with a linear force transducer (a Kistler 6123 piezoelectric pressure transducer) placed at $1.5 \mathrm{~mm}$ in front of the

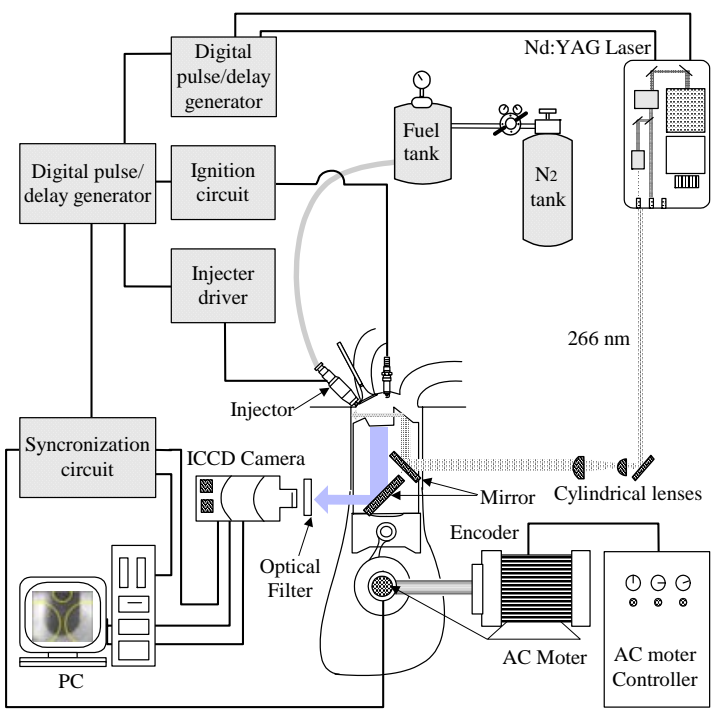

Figure 3 Experimental setup for the visualization of flames and mixture distribution injector tip.

Experimental setup for the flame visualization and PLIF measurements is shown in Fig. 3. The PLIF images were digitally recorded with an intensified-CCD (ICCD) camera that provided 640 by 480 pixel images at a resolution of 8bits. For the flame visualization, the bottom view window and $45^{\circ}$ degree mirror were used. For the PLIF experiments, the laser light sheet was induced inside of the piston bowl by the $45^{\circ}$ degree mirror and optical prism. The fourth harmonic of the $\mathrm{Nd}$ :YAG at 266nm was used to excite dopants. Base fuel and dopant used were iso-octane and 3 -pentanone, respectively. Their mixing ratio was $80 \%$ iso-octane and $20 \% 3$-pentanone by volume.

\section{Results and discussion}

\subsection{Mass flow rate}

Mass flow rate measurements were performed to determine the injection duration required to meter a given amount of fuel for an injector with two different injection drivers. The results of the experiments, on a per injection basis, are shown in Fig. 4. Each curve represents a different injector driver. To determine the injection duration required for the preset air-fuel ratio, the metering data in Fig. 4 were curve fit. The amounts of injection for types A and B were measured by weighing over 1000 injections at short injection times (less than $1.0 \mathrm{~ms}$ ) and 100 injections for the longer injection time. The equations noted on Fig. 4 represent linear regressions of the data. Correlation coefficients were greater than 0.99 in all cases.

In addition to metering experiments, injection rate measurements were performed using the method introduced by Naber et al. [7]. Rate of injection experiments give a time history of fuel mass emitted during an injection event. Figure 5 shows the results of the injection rate measurements. The vertical dotted lines on each curve represent the end of injection control signal. The time lag between the control signal (time zero) and the initial climb in the rate of injection is due to a delay associated with each injector driver. The time lags for two injector drivers (types A 


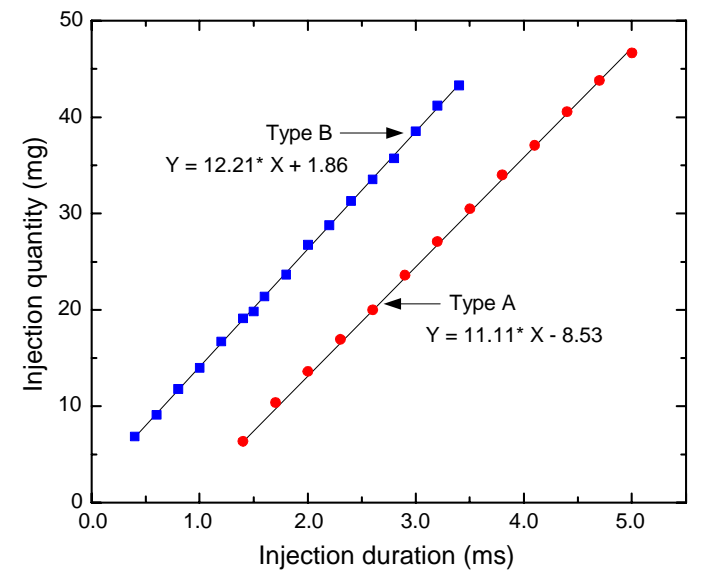

Figure 4 Fuel metering as a function of injection duration

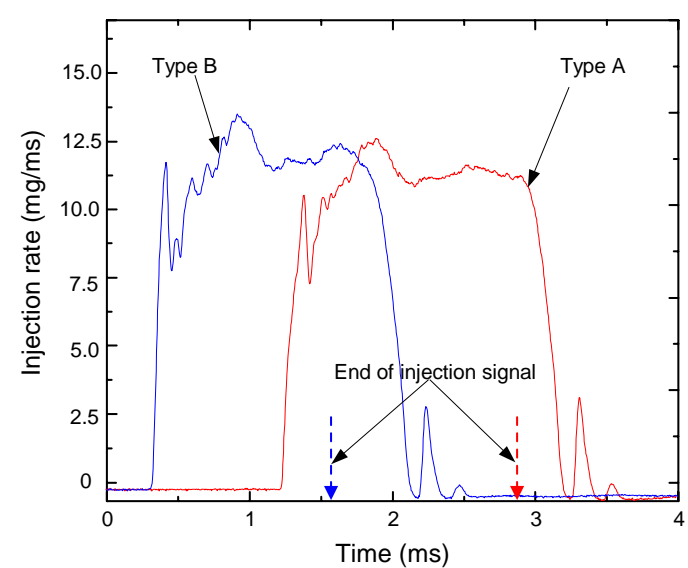

Figure 5 Rate of injection curves for two different injector drivers

and B) were found to be approximately $0.26 \mathrm{~ms}$ and $1.25 \mathrm{~ms}$, respectively. Each rate of injection curve exhibits transient behavior at the beginning and end of the injection event. Between these two transient features the rate of injection is nearly constant. The first peak could result from a leading mass followed by the main spray [8]. The slope of the initial climb of type B is steeper than that of type A. This indicates that type B has a bigger mass flow rate than type A at the early stage of injection. In addition, the time approaching the steady mass flow rate of type B is faster than that of type A. Another peak in injection rate curve after the end of injection is likely due to some needle bounce. For the stratified combustion, the initial mass flow rate is very important since the mixing time between the injected fuel and intake air is not sufficient. Thus, the effect of two different mass flow rates on combustion and mixture distribution was investigated in the following sections.

\subsection{Combustion characteristics}

\subsubsection{Analysis of in-cylinder pressure}

To evaluate the effect of the difference of the initial mass flow rate, the combustion analysis was carried out to estimate IMEP, Coefficient of Variability of IMEP (COV $\left.\mathrm{IMEP}_{\mathrm{I}}\right)$ and mass fraction burned (MFB) from in-cylinder pressure data. Figure 6 shows IMEP and $\mathrm{COV}_{\text {IMEP }}$ as a function of injection timing for the injector drivers of types $A$ and $B$. Error bars represent $\mathrm{COV}_{\text {IMEP. For both }}$ types, MBT ignition timing was at $25^{\circ}$ BTDC. IMEP of type A decreases with the injection timing advance while that of type $B$ increases. However, IMEP of type B has higher values than that of type A for all injection timings. This result indicates that the higher initial mass flow rate leads the bigger IMEP. To examine combustion duration, MFB was calculated. The results of the analysis of mass fraction burned were summarized in Table 2 . Negative and positive values mean before top dead center and after top dead center at a compression stroke, respectively. The slopes of the mass fraction burned for type A is smoother than those for type B with a higher mass flow rate. In particular the 50\% mass fraction burned for best cases of both types is well positioned at 5-10 $0^{\circ}$ ATDC. As the injection timing is retarded, the burn duration of type $\mathrm{A}$ is

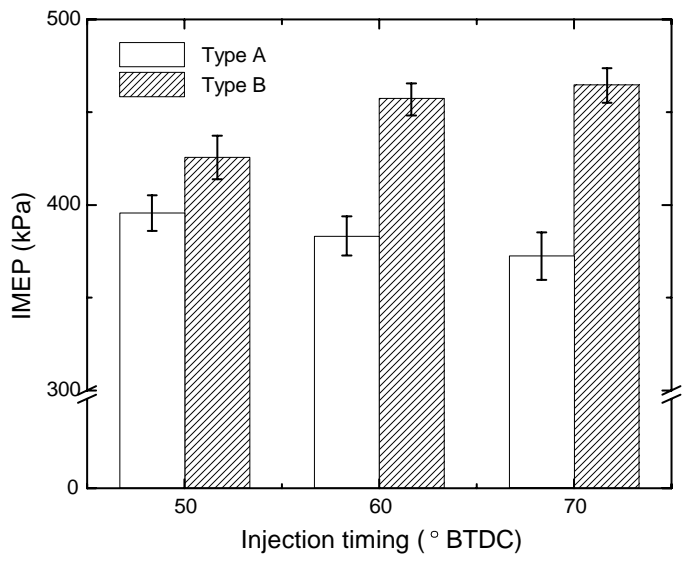

Figure 6 IMEP with COV of IMEP for two different drivers 
Table 2 Combustion durations for two different mass flow rates

\begin{tabular}{l|c|c|c|c|c|c}
\multirow{2}{*}{$\begin{array}{c}\text { Injection } \\
\text { Timings }\end{array}$} & \multicolumn{3}{|c|}{ Type A } & \multicolumn{3}{c}{ Type B } \\
\cline { 2 - 7 } MFB & $50^{\circ}$ BTDC & $60^{\circ}$ BTDC & $70^{\circ}$ BTDC & $50^{\circ}$ BTDC & $60^{\circ}$ BTDC & $70^{\circ}$ BTDC \\
\hline \hline $10 \%\left({ }^{\circ} \mathrm{CA}\right)$ & -0.7 & -0.8 & 1.4 & -4.1 & -4.6 & -0.5 \\
\hline $50 \%\left({ }^{\circ} \mathrm{CA}\right)$ & 9.8 & 10.0 & 13.3 & 3.4 & 4.1 & 8.9 \\
\hline $90 \%\left({ }^{\circ} \mathrm{CA}\right)$ & 22.0 & 21.7 & 25.0 & 15.5 & 15.9 & 18.4 \\
\hline Burn dur. $\left({ }^{\circ} \mathrm{CA}\right)$ & 22.6 & 22.6 & 23.6 & 19.6 & 20.5 & 18.9 \\
\hline Slope & 17.0 & 17.1 & 16.4 & 19.7 & 18.8 & 20.7 \\
\hline
\end{tabular}

shorter while that of type B becomes longer. Thus, the case of type B with higher mass flow rate showed faster combustion, higher IMEP and lower $\mathrm{COV}_{\text {IMEP }}$ as shown in Fig. 6.

\subsubsection{Initial flame development}

To observe flame shape and size at the initial stage of combustion, flame visualization by self luminescence at this stage was performed with ICCD camera. Two representative cases, which are best IMEP cases for both types of injection driving units, are shown in Fig. 7. Five images for each case were averaged and flame front was detected by an image processing. One is the case of $50^{\circ}$ BTDC injection timing for type $\mathrm{A}$. The other is the case of $70^{\circ}$ BTDC injection timing for type B. As shown in Fig. 6, IMEP of the latter case is higher than that of the former case. Each number indicates crank angle degree before TDC. The flame propagates downwardly. The flame speed of type B is slightly faster than that of type A. At the early stage from $23^{\circ}$ BTDC to $19^{\circ} \mathrm{BTDC}$, the flame size for type B is bigger than that for type $\mathrm{A}$ and the flame shape is more regular. After the early stage, flame spread outside of the observation area. These results imply that the case with faster mass flow rate has more sufficient mixing time resulting in stable combustion.

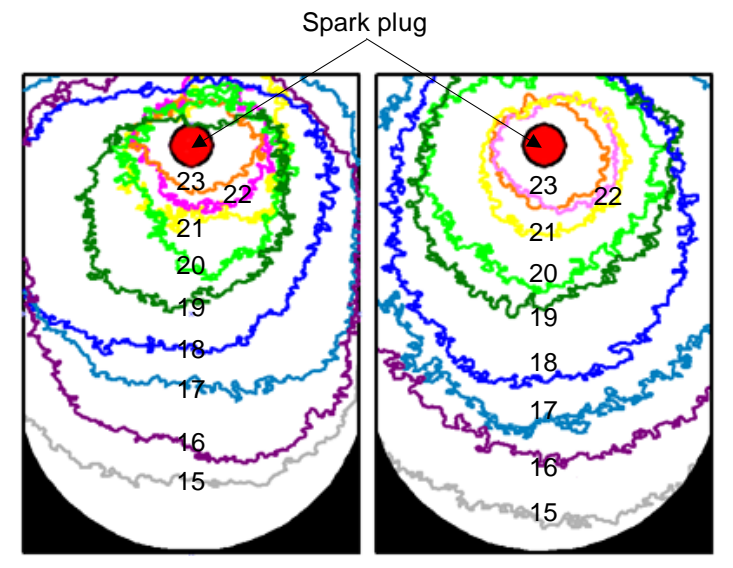

(a) Type $\mathrm{A}$ $50^{\circ}$ BTDC injection (b) Type B $70^{\circ}$ BTDC injection

Figure 7 Initial flame development

\subsection{Fuel distribution}

To examine mixture distribution prior to combustion, PLIF technique was employed. The image processing was done on a set of ten images for each condition. The images were scaled for laser power and camera gain, normalized using the measured vertical sheet profile and then averaged. Figures 8 and 9 show the relative fluorescence intensity along the vertical center line and the horizontal line with a spark plug. To compare each mixture distribution, the intensity was normalized by the maximum value of all cases. Due to inducing the laser sheet through the bottom window and prism, the position of laser sheet varies with crank angle. Figure 8 (a) and (b) are same condition as shown in Fig. 7.

For type A, the high intensity de to the fuel injected appears at $46^{\circ}$ BTDC. As the crank angle advances, the dense mixture moves to the spark plug due to the piston wall and intake tumble motion. The intensity near spark timing was about 0.3 . For type $\mathrm{B}$, no fuel was observed at $46^{\circ}$ BTDC owing to the retarded injection timing. Due to the same mechanism, the mixture concentrates near the spark plug. However, the intensity near spark timing was about 0.5 , which is bigger around 1.6 times of type A. This results in higher IMEP value as described in 3.2.1. 


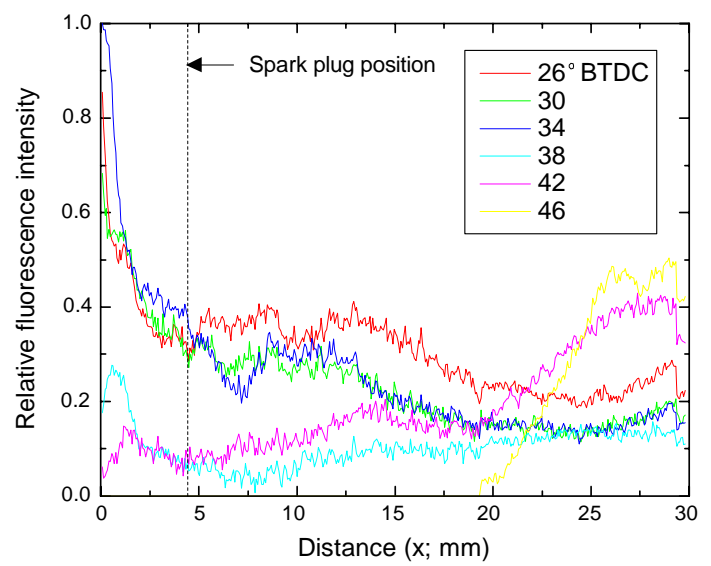

(a) Type A

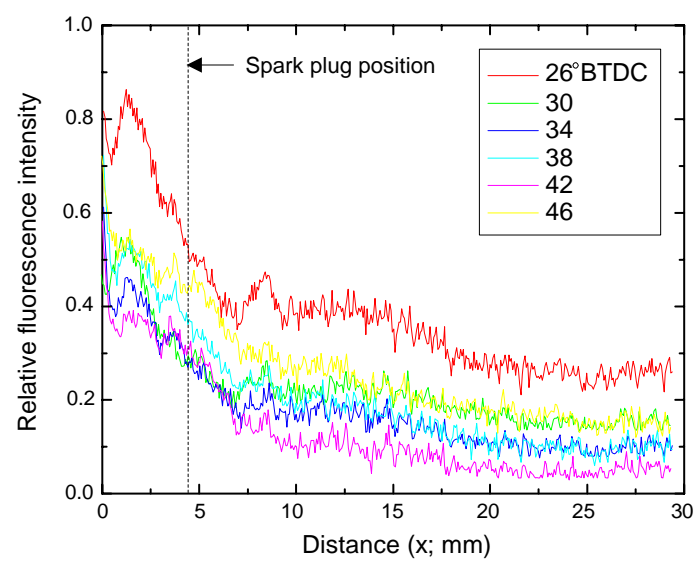

(b) Type B

Figure 8 Fluorescence intensity along the vertical center line through spark plug

Although the graph of horizontal intensity profiles is not shown in this paper, the intensity for type $\mathrm{B}$ distributes more uniform and is higher than that of type A. These results imply that more stable stratified combustion process could be achieved.

\section{Summary}

The effect of the mass flow rate on stratified combustion was investigated by the analysis of combustion characteristics, flame visualization and PLIF measurements indicating the mixture concentration distribution. The main findings are summarized as follows:

(1) As the mass flow rate has a higher value, more stable and faster combustion was achieved.

(2) The initial flame size and shape for higher mass flow rate are bigger than that of lower mass flow rate.

(3) The mixture distribution showed more uniform and higher concentration in the bowl near the spark plug as the mass flow rate increases.

\section{Acknowledgments}

This research was supported by NRL (National Research Laboratory) scheme, Ministry of Science and Technology, Korea.

\section{References}

[1] Zhao F, Lai MC and Harrington DL 1999 Prog. Eng. Comb. Sci. 25 437-562

[2] Cousin J, Ren WM and Nally S 1998 SAE Paper 980499

[3] Tabata M, Kataoka M, Tanaka T and Yamakawa M 2000 SAE Paper 2000-01-0240

[4] Shayler PJ, Jones ST, Horn G and Eade D 2001 SAE Paper 2001-01-3671

[5] Miyamoto N, Ogawa H, Shudo T and Takeyama F 1994 SAE Paper 940675

[6] Harada J, Tomita J, Mizuno H, Mashiki Z and Ito Y 1997 SAE Paper 970540

[7] Naber JD and Siebers DL 1996 SAE Paper 960034

[8] Parrish SE and Farrell PV 1997 SAE Paper 970629 